Portland State University

PDXScholar

Dissertations and Theses

Dissertations and Theses

1976

\title{
Male Client Expectations of Female Therapists
}

Phyllis Whitman Heims

Portland State University

Susan Annette Ofstad

Portland State University

Follow this and additional works at: https://pdxscholar.library.pdx.edu/open_access_etds

Part of the Social Work Commons

Let us know how access to this document benefits you.

Recommended Citation

Whitman Heims, Phyllis and Ofstad, Susan Annette, "Male Client Expectations of Female Therapists" (1976). Dissertations and Theses. Paper 1868.

https://doi.org/10.15760/etd.1867

This Thesis is brought to you for free and open access. It has been accepted for inclusion in Dissertations and Theses by an authorized administrator of PDXScholar. Please contact us if we can make this document more accessible: pdxscholar@pdx.edu. 


\title{
MALE CLIENT EXPECTATIONS \\ OF FEMALE THERAPISTS
}

\author{
by \\ PHYLLIS WHITMAN HEIMS \\ and \\ SUSAN ANNETTE OFSTAD
}

A practicum submitted in partial fulfillment of the requirements for the degree of

\author{
MASTER OF \\ SOCIAL WORK
}

Portland State University
1976 
The advisor approved this practicum presented May 28, 1976. 


\section{ACKNOWLEDGEMENTS}

We would like to express our appreciation to Nancy Koroloff for her patience, direction, and support, to the PSU Counseling Center for their cooperation and assistance, and to two special friends, Jack and Tom, for just being there. 
TABLE OF CONTENTS

PAGE

ACKNOWLEDGEMENTS .............................

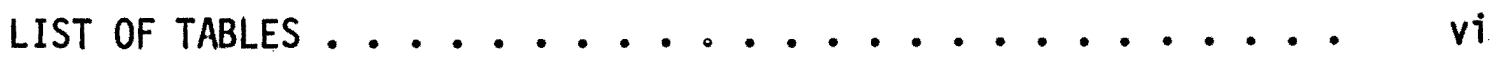

CHAPTER

I INTRODUCTION ................................. 1

II LITERATURE REVIEW ................... 3

Client Expectations............ 3

Importance of Expectations

Social and Cultural Influences

on Expectations

Relationship of Preferences to

Expectations

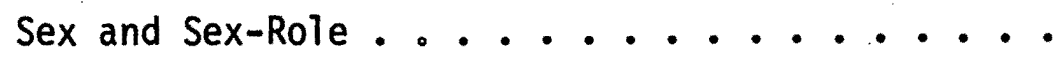

Sex of the Therapist and $\mathrm{Cl}$ ient

Effect of Sex-Role

III CONCEPTUAL FRAMEWORK. ................... 15

Development. ................. 15

Evaluation ....................... 23

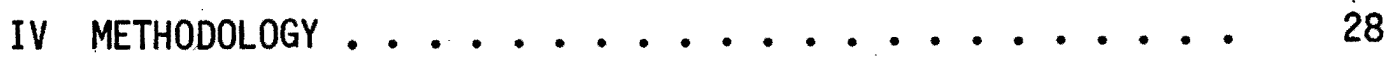

Research Design. .............. 28

Definition of Terms.............. 29

Development of Questionnaire ........ 31

Questionnaire Format

Pre-Test

Sampling . . . . . . . . . . . . . 
The Agency

The Sample

Data Collection ............ 34

Data Analysis ................. 36

V RESULTS............................... 37

Description of the Sample ......... 37

Results According to Expectation Categories .... 41

VI CONCLUSIONS AND IMPLICATIONS . . . . . . . . . 50

Conclusions Regarding General Results...... 50

Conclusions Regarding Hypotheses. . . . . . 52

Implications.............. 55

LIST OF REFERENCES . . . . . . . . . . . . 58

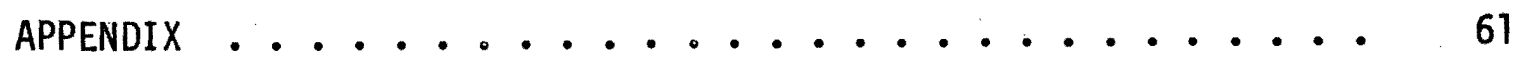




\section{LIST OF TABLES}

TABLE

PAGE

I Total Number of Questionnaires per Category . . . .

II Means and Standard Deviation of the Ages of the clients....................... 37

III Frequency of Clients According to Year in School. . . 38

IV Percentage and Frequency of $\mathrm{Clients}$ with Prior Counseling Experience .......... 39

$\checkmark$ Sex of Therapist in Prior Counseling Experience . . . 40

VI Sex of Therapist Preferred For Current Counseling Experience............... 40

VII Means For Items Within the Nurturing Category . . . . 42

VIII Means of the Manipulation Category. . . . . . . 43

IX Means of the Assertiveness Category . . . . . . . 44

$X$ Means of the Non-Judgmental Category. . . . . . 45

XI Means of the Understanding Emotions Category. . . . . 46

XII Means of the Competence Category. ......... 47

XIII Means of the Life Experience Category . . . . . . . 48 


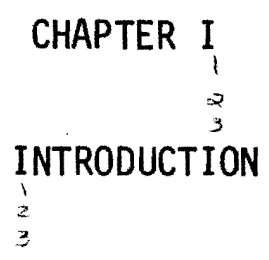

This practicum intends to explore the existence and nature of male client expectations of female therapists. The underlying assumptions of this study include: (1) clients have expectations; (2) sexroles exist in society; and (3) the sex of either the therapist or the client is a variable in the therapeutic situation.

For the purpose of this study, an expectation refers to the client's anticipated perception of the therapist prior to the initial interview. Numerous researchers support the existence of client expectations and perceptions prior to therapy (Bordin 1955, Lorr 1965, Grosz 1968, Gladstein 1969).

Sex-role is the societal assignment of certain tasks and personality traits on the basis of sex. An individual's perception of the role ascribed to men or women may vary with their own socialization process (Horton and Hunt 1964).

It is the experience of these authors and their colleagues that in most therapeutic settings both male and female therapists deal with $\mathrm{cli-}$ ents of the opposite sex. In addition, the sex of the therapist and the sex of the client are variables affecting both the therapeutic process (Fuller 1963, Brooks 1974) and the initial interview (Kadushin 1958). Having considered the above assumptions -- that client expectations exist, that sex-roles exist in society, that therapists deal with clients of the opposite sex, and that the sex of either the therapist or 
the client is a variable in the therapeutic situation -- it is hypothesized that client expectations may be affected by the sex of the therapist. Because of a personal interest in the role of the female therapist in relating to male clients and because there is little literature focused on this aspect, this study will explore the existence and nature of expectations specifically held by male clients of female therapists.

To carry out this study it is necessary to pursue the following tasks. The first step will be to define possible client expectations of therapists. Using this information, a questionnaire will be developed to verify the existence of these expectations. In addition, the questionnaire will hopefully indicate whether these expectations vary according to the sex of the therapist and whether these expectations vary with the sex of the client. The intention of this study is to yield data that will allow for conclusions regarding sex as a variable affecting client expectations, specifically male client expectations of female therapists. 
CHAPTER II

\section{LITERATURE REVIEW}

In reviewing past studies and articles, it was found that there was little literature dealing specifically with male client expectations of female therapists. Subsequently, it was decided to review literature on two aspects, client expectations and the influence of sex and sex-role. The discussion on client expectations will focus on the importance of expectations, the social and cultural influences on expectations, and the relationship of preferences and expectations. The second section will review the effect that the sex of the therapist and of the client has on the therapeutic situation and the effect of sex-role.

\section{CLIENT EXPECTATIONS}

Importance of Expectations. In reviewing the literature regarding client expectations of therapists, it became apparent that expectations not only exist, but also have an impact on the therapeutic situation and appear to be an influential factor for therapists to consider.

Bordin (1955) points out that the personal characteristics expected of counselors are most significant for clients who come in for counseling about personal problems, as opposed to clients who are seeking counseling for informational reasons. He feels that client expectations affect the counseling process and suggests that studies need to be done to identify specific expectations. Kelly (1955) states that the way the client conceptualizes the therapeutic situation affects the role he sees 
himself playing and the role he anticipates the therapist playing. This affects his behavior in early interviews.

Lorr (1965) says that perceptions and feelings of clients towards their therapist affect the therapeutic relationship. These perceptions are affected by client expectations prior to therapy. Lorr's study shows that two perceptions, understanding and acceptance, are related significantly to improvement in therapy.

Appe1 (1960) and Chance (1959) believe that clients have expectations of psychotherapists' behavior and psychotherapists have expectations of clients' behavior. They feel that the degree of interdependence and mutuality of these expectations influence client interview behavior (Appel) and the outcome of therapy (Chance).

Having reviewed the impact of client expectations of therapists in the therapeutic situation, it is now appropriate to explore what specific expectations have been identified. Holt (1950) finds that students generally perceive a counselor as a father figure; advice giving, source of information, and playing a more directive role in problem solving. Kelly (1955) states that expected role may include "... parent, protector, absolver of guilt, authority figure, prestige figure, a possession, a stabilizer, a temporary respite, a threat, an ideal companion, and a representative of reality ..." Lorr (1960) studies dimensions of client perceived behavior of therapists in the counseling interview. Behaviors clients identified are classified into the following five categories: acceptance, understanding, authoritarian, independence-encouraging, and critical-hostile.

Apfelbaum (1958) in his study of expectations uses a cluster anal- 
ysis of Q-sort items to determine patient role expecations. The expectations cluster around these three dimensions: (1) nurturant, giving, protective, non-critical, non-businesslike, not expectating patients to shoulder responsibilities; (2) model, neither judges nor evaluates, tactful, permissive listener, neutral, neither critical nor protective; and (3) critic, critical, analytical, expects patient to take a lot of responsibility, neither gentle nor indulgent. He points out that the males in his sample have a marked tendency to prefer a "critic type" therapist as compared to females who expect a "model type" therapist. A similar observation is made by Tan (1967) who found that male subjects tend to expect a more authoritarian counselor than did their female counterparts.

Chance (1959) focuses on the mutuality of client and therapist expectations. She categorized five of the most frequent client expectations of therapists, which include: advice giving, helpful, leading, sympathetic, and affectionate. The next most frequent are: appreciative, liking to be liked, cooperative, and trusting. In very few instances, clients identify the negative expectations of being accusing, resentfur, and nagging.

Appel (1960) studying voluntary clients at a student counseling center finds that they have optimistic, almost overconfident expectations of the therapists' capabilities to help them.

In a study by Thomas et al. (1955), the client's expectations regarding therapist's motivation is investigated. It is found that clients who expect the therapists to be highly motivated to help them, as opposed to therapists who are less motivated to help them, anticipate 
the following behaviors: (1) the therapist would assign importance to client's problems; (2) the therapist would be more willing and unambivalent about maintaining communication with clients; $(3)$ the therapist would be willing to admit more areas of communication into therapy; (4) the therapist would have more influence over the subject matter; and (5) the client would be more likely to continue in therapy.

Social and Cultural Influence on Expectations. Although there are many influences on the development of client expectations, in this study it seems significant to review some of the social and cultural influences. As indicated in the introduction, sex-role is a societal phenomenon. Because the purpose of this study is to determine the relationship of sex-role to client expectations, it seems beneficial to review social and cultural influences on the development of expectations.

Form (1953) suggests that students' attitudes toward counselors may be influenced by social factors such as sex, socio-cultural background and economic level. Similarly, Patterson (1958) states that expectations and preferences of clients in counseling and psychotherapy are socially and culturally determined. Sonne and Goldman (1957) recognize that in our culture in general, relatively dependent relationships between a psychological helper and a counselee may be the norm. This norm has its roots in society's attitudes towards specialists, i.e., doctors, lawyers, and engineers; who are identified as authority figures, doing things to us or for us or telling us what to do and how to do it. These attitudes may influence clients' expectations of the helping person. In an inter-cultural study with Asian and American students, Tan (1967) finds that the expectations of Asian students coming from an 
authoritarian-oriented country differ from the expectations of American students. Asian students expect counselors to be more authoritarian, direct, and nurturant, while their role as client is to be more submissive.

Kadushin (1958) points out that the therapeutic relationship is a social-psychological situation but that the social aspects take priority in the initial contacts. Because the client has little knowledge of his new role, he relies on familiar social roles which may be based on age, race, class or sex. In this article, Kadushin focuses on the variable of sex, specifically a male client with a female social worker. He proposes that the male client responds to this unfamilar situation by referring to past similar situations, i.e., a male to female encounter. His responses will be based on his conception of the female social role, and responses supported and learned in his reference group. This stereotyped response is altered as the therapist helps the client learn his new role, and as the therapist is seen as an individual apart from those roles.

In concluding these two sections, it is necessary to note the implications these articles and studies have for this particular study. The most obvious limitation of all these articles is the exclusion of sex as a major variable as it relates to expectations. Only two articles differentiate between male and female expectations held of therapists (Apfelbaum and Tan). However, in both of these studies, these differences were secondary observations. Kadushin makes a strong statement about the sex of the therapist and sex-role as they relate to initial interviews, but his statements are not substantiated by empirical research. 
Apart from the above limitations, there are a number of reasons to question the applicability of these articles to our study. While Form, Patterson, and Bordin raise a number of relevant issues, they speak in general terms and do not support their statements with empirical evidence. Although Thomas et al. is specific in studying one expectation, the study is contrived because he does not use actual clients and creates hypothetical attitudes toward the counselors. A number of articles do use actual clients, but have other drawbacks. Lorr, while making the connection between perceptions and expectations, studied client's perceptions during therapy rather than expections prior to therapy. Tan, Chance, and Appel study expectations as dependent on other variables such as inter-cultural influences and mutuality.

The most relevant article is Apfelbaum's study because he deals with actual clients in an outpatient clinic and he measures client expectations prior to the therapeutic encounter. The major disadvantage, as previously stated, is his failure to consider the sex and sex-role of the therapist and of the client.

However, there are values in this review that relate to this current study. The volume of literature written on expectations supports the importance of a study on the effect of expectations. In addition, it indicates the impact expectations have on the therapeutic encounter and the need for therapists to consider expectations when doing therapy. The review of specific expectations that have been identified provides these researchers with guidelines regarding the extent and nature of client expectations. This is helpful in identifying areas to be included in our study. It has been beneficial to investigate articles which 
validate the societal and cultural influences on expectations. Kadushin, especially, makes an important connection that socialization affects sex roles and that expectations based on these sex roles affect the initial interview. This concept supports our assumption that sex roles affect expectations.

Relationship of Preferences to Expectations. Boulware and Holmes (1970) establish a strong relationship between preferences expressed for potential therapists and the expectancies subjects have of those therapists. Their preferences are based on "therapy relevant expectancies." Their study is based on age and sex with their results showing older males to be most preferred. This preference is based on the "therapy relevant expectancies" of competence, understanding, advicegiving, experience, and knowledge. The second most preferred therapists are younger males who are seen as being most similar to the subjects in experience and attitudes. The study is based on vocational and personal problems and the only exception to the above results is that female subjects with personal problems prefer older women. Boulware and Holmes' results, that male therapists are preferred, is congruent with studies by Levy and Iscoe (19.63), Fuller (1964), and Simon (1973). The results of these studies support the connection these researchers are making between expectations and sex.

\section{SEX AND SEX-ROLE}

3 Sex of The Therapist and Client. Schwartz (1974) examines articles found in the journal Social Work for the past eight years to determine the profession's awareness of the issue of the sex of the therapist 
and the sex of the client. She finds the subject to be generally ignored or viewed from a unisex perspective, in which the two sexes are undifferentiated. She sees this as unrealistic. She also questions whether positive results in therapy are based on the therapy itself or if the sex of the therapist and client are important variables which are seldom considered. She hypothesizes certain situations in which she feels sex would be a significant variable. For example, when a male client is relating to a female therapist, he may find it difficult to cry and deal with vulnerable feelings, or difficult to accept help with financial problems. The importance of sex is further supported by her observation that female social work students experience difficulty working with male clients, especially those with "an exaggerated form of stereotyped male behavior." She feels this is accentuated if the student is struggling with her own stereotype definitions of sex. She concludes that the role of sex has neither been integrated into professional thinking nor has it been recognized as a significant variable as has race and socio-economic class.

Schwartz notes a study by Pew, Speer, and Williams (1973) as an exception to these findings. They find that using male and female cotherapists is an important variable in the therapeutic process. In working in groups with male and female offenders, they recognize heterosexual problems as being universal. By using a male and female co-therapist, they find that: (1) when problems were discussed, one or the other of the therapists could usually understand; (2) young women in the group were better able to verbalize their concerns because of the support of the female therapist; (3) clients observed role modeling that 
challenged previously accepted roles of women being subservient; and (4) group nembers were exposed to a new kind of male-female interaction as demonstrated by the co-therapists. They observed that men and women could disagree and still respect each other, which helped the group change previous biases.

Two studies emphasize the influence of the sex of the therapist and the sex of the client on the therapeutic situation. Fuller (1963), in studying the influence of sex as it relates to the client's expression of feelings, found that females expressed more feelings than males with a counselor of either sex. In addition, more feelings were expressed in counselor/client pairings if one of the pair is a female. Brooks (1974) studies the influence of sex of the client and therapist on self-disclosure. She finds that: (1) subjects disclosed more about themselves in counselor/client dyads containing a female; and (2) female clients disclosed less with female counselors and that male clients disclosed less with male counselors. She implies from these results that self-disclosure may be either inhibited by same sex dyads or facilitated by opposite sex dyads.

In summary, the importance of the sex of therapist and sex of client has been raised as an issue by the articles discussed in this section. Schwartz points out the lack of emphas is on sex by the social work profession. She supports these researchers in their study of sex as a significant variable in the therapeutic situation. In addition, it is important to this study to note the impact of sex as demonstrated by Pew et al., Brooks, and Fuller. It seems that the influence of sex needs to be recognized if therapy is to be expedient and productive. Although 
these studies point out the significance of sex, none of them deal with sex as it relates to expectations.

Effect of Sex-Role. Broverman, Voge1, Broverman, Clarkson, and Rosenkrantz (1972) examine the nature and effects of sex-role in contemporary society. They define sex-role as "... the sum of socially designated behaviors that differentiate between men and women ..." The specific characteristics attributed to the male sex-role cluster around "competency," which includes being independent, objective, active, competitive, logical, skilled in business, worldly, adventurous, decisive, self-confident, a leader, and ambitious. The role stereotype characteristics for women cluster around "warmth and expressiveness" defined as gentle, sensitive to other's feelings, tactful, religious, neat, quiet, interested in art and literature, and able to express tender feelings. They state that:

Despite the apparent fluidity of sex-role definitions in contemporary society, our findings to date confirm the existence of pervasive and persistent sex-role stereotypes, which cut across age, socio-economic status, marital status, sex, and educational levels.

These findings are further exemplified in their second study entitled "Sex-Role Stereotypes and Clinical Judgements in Mental Health" (Broverman et a1.). The results of this study indicate that clinicians have different concepts of mental health for men and women, and these differences parallel the sex-role stereotypes prevalent in our society. In this study clinicians were asked to define their concepts of a healthy mature adult, a healthy mature male and a healthy mature female. It was found that their concept of healthy mature adults included the same 
traits as their concept of a healthy male. However, their concept of a healthy mature female differs from that of a healthy adult.

Miller (1974) further studies the influence of patient's sex on clinical judgment. In this study, clinicians identified passivity as the major problem for both male and female clients. However, this passivity was more often viewed as a focus for treatment with male patients than with female patients.

In examining the above articles as they relate to this study on expectations, Broverman et al. supports the assumption of these researchers that sex-roles are prevalent in our society and that they are socially determined. Secondly, Broverman et al. concludes, as does Miller, that sex-roles affect clinicians' judgment of their clients. If sexroles significantly influence clinicians' judgments of clients, it seems logical that, in turn, sex-roles would also influence client's perceptions of therapists. Kadushin, as previously discussed (pg. 7), strongly supports this concept.

Although Broverman's et a1. studies strongly support the impact of sex-roles on the therapeutic situation, their applicability to the study on expectations is limited. This is because their study specifically deals with clinician's views of clients and because they deal with a specific set of sex-role stereotypes. It is important to this current study to avoid establishing a pre-set notion of existing sexrole stereotypes.

Summary. In searching for literature regarding male client expectations of female therapists, it has been found that the helping professions have seldom recognized a relationship between sex and expecta- 
tions. As shown in this review, expectations and sex of the therapist and client have a significant impact on the therapeutic situation. Furthermore, sex-roles actively define an individual's perceptions and behaviors based on his or her socialization process. Because sex-roles affect perceptions and behavior, it seems logical to assume that sexroles would also affect expectations in the therapeutic situation. If these conclusions are true, then it is important to understand the nature and extent of these expectations. 
CHAPTER III

\section{CONCEPTUAL FRAMEWORK}

\section{DEVELOPMENT}

Because this study is exploratory in nature, it seems helpful to investigate a number of sources of information in developing a conceptual framework for a study of male client expectations of female therapists.

An initial source of information was a Conference of Women in the Human Services held in Eugene, Oregon, in June 1975. The conference was attended by women who were professionals or paraprofessionals working in the human services. The workshop that was most applicable to this study dealt with client expectations of female therapists in which participants shared their perceptions and experiences. They saw clients expecting female therapists to: be easily manipulated; be less competent; be nurturing and gentle; have less decision-making power in an agency; fulfill needs rather than promote growth; know less about client's life experiences than a male therapist of a similiar age; and be too emotional as opposed to logical. In general they felt that female therapists were expected to behave according to sex-role stereotypes, were often seen as a "mother" by the clients, and were not always seen as being a "real woman." At the conference these expectations were not differentiated according to the sex of the client.

This workshop assisted these researchers in specifying a list of expectations for further study which was divided into "mother" expecta- 
tions and "female role" expectations. Client expectations that defined the female therapist in the "mother" role included that she would be nurturing, sympathetic, non-judgmental, and capable of understanding emotions. Client expectations which supported the female sex-role stereotype included that she would be less confrontive, more easily manipulated, less assertive, less competent, less logical, and less understanding of male client's life experiences.

The conference stimulated ideas regarding client expectations. However, it seemed necessary to confirm whether other practicing female therapists considered these expectations to be realistic. Thus, the second source of information was interviews with practicing female therapists.

The twofold purpose of interviewing female therapists was as previously stated, to verify expectations discussed at the conference and to explore other possible expectations. The female therapists chosen for these interviews were professional women, currently doing therapy in a voluntary clinical setting, with the exception of one therapist who was working in a state agency. The therapists included one psychiatrist, two psychologists, and four social workers with Master degrees. The age range of the therapists interviewed was 27 to 48 years, with the median age being 33 years. All therapists have worked in Mental Health Programs for at least two years, with the exception of the one woman who worked in Public Welfare. Four therapists worked primarily with urban clientele, while three worked with clients from both urban and rural settings. In looking at the socio-economic class of the clientele, two therapists described their clients as middle class, two described the 
majority of their clients as lower class, and three described their clients as mixed, lower and middle class. A11 therapists saw male and female adults while one also saw a significant number of adolescents. Most therapists saw more female clients than male clients, which reflected the client population of their agencies.

The interview schedule included both open-ended and close-ended sections. The purpose of the open-ended section was to generate further expectations based on the experience of these therapists. The two basic questions for this section were:

1. Do male clients have expectations of you as a female therapist and if so, what are they?

2. Do you think these expectations differ from what male clients expect of male therapists and if so, how do they differ?

To elaborate on the open-ended section, a brief summary of the interview with each therapist will follow.

Therapist No. 1 is a 35 year old MSW, working in a public welfare agency, who spends only $10 \%$ of her time in therapy with individuals, couples, and families. Because she is employed in an agency that primarily meets daily living needs, i.e., housing, money, fuel, etc., she feels that both male and female caseworkers are seen by male clients as nurturing. However, she felt male clients are more inclined to ask women caseworkers for extra things than they are male caseworkers. She feels that male clients see her as gentle, mild-mannered, and non-threatening. However, she finds it hard to differentiate whether their expectations are based on her femaleness or her personality. 
Therapist No. 2 is a 27 year old MSW who spends $50 \%$ of her time in therapy and of that, $3 / 5$ is spent with individuals, couples, and families, and $2 / 5$ is spent in groups. She definitely believes that there are differences in male client expectations of male and female therapists. She feels males expect female therapists to be supportive, be motherly, allowing them to ventilate, be less confrontive, and to provide security and warmth. She also feels that males tend to see female therapists as not giving them enough direction or strong enough to handle their problems. She hypothesizes that male clients may find relating to a male therapist difficult because they may feel more competitive or threatened. Those life experiences that she feels a male client may expect her not to understand include: sexual problems, problems with women, expectations of the "breadwinner" role, the role as father, and a male's difficulty in expressing feelings.

Therapist No. 3 is a 29 year old MSW who spends $40 \%$ of her time in therapy and of that, $2 / 3$ is spent with individuals, couples, and families, and $1 / 3$ is spent with groups. She feels that it is a minority of male clients that have differing expectations of male and female therapists. Of those who do, she feels they expect her to be soft and caring, more understanding than male therapists, more of a "pushover" in terms of manipulation, and may expect her to be too weak to handle their problems. She feels they often see her as "mother"; however, she surprises them by being confrontive and assertive. She suspects that clients play stereotypic roles; therefore, they expect the therapist to do so as well. She also suspects that male clients may feel more competitive with male therapists. Those life experiences she feels a male 
client may expect her to have difficulty understanding include: the pain of trying to date women, the pressure of the societal expectation that a man support his family, and sexual problems.

Therapist No. 4 is a 48 year old psychologist who spends $30 \%$ of her time in therapy, of which $4 / 5$ is spent with individuals, couples and families, and $1 / 5$ is spent in groups. She identifies herself as a "nondirective therapist." Therefore, she chooses to be non-confrontive and non-assertive in therapy. She sees male clients as being conditioned by our society to be stoic in terms of emotional expression, which causes problems for them in relationships. They are also conditioned to be self-sufficient in handling personal and family problems; thus, it is difficult for them to seek outside help. She suspects that it is difficult for a man who is dealing with strong expectations from his father, to deal with a male therapist.

She hypothesizes that if a therapist projects what she thinks a: client will expect of her, the client may respond accordingly, fulfilling those expectations. In light of her own professional experience, she feels that as she has become assured of herself as a therapist, client expectations have become less of an issue.

Those life experiences which she feels male clients expect her to have difficulty in understanding include: their work and career experiences, and their role as father and husband in the family.

Therapist No. 5 is a 33 year old psychologist who spends $70 \%$ of her time in therapy, of which all is spent with individuals, couples, and families. She strongly feels there are no differences in male client expectations of male and female therapists. She also strongly feels 
she cannot project male client nor male therapists' experiences. However, she feels that as a woman becomes more competent as a therapist and assured of herself as a woman, possible client expectations become non-existent. The only life experience she feels that male clients do not expect her to understand is their military experiences.

Therapist No. 6 is a 34 year old MSW who spends $65 \%$ of her time in therapy, of which $2 / 5$ is spent with individuals, couples, and families, and $3 / 5$ is spent in groups. She feels that all clients have expectations of therapists but that they may not differ because of the sex of the therapist. She feels that clients often project parental images onto therapists. The image of either parent may be projected on a female therapist, depending on which parent the client has unresolved feelings about. She also believes that all clients try to manipulate therapists because that is how people have learned to get their needs met. She feels there is a cultural stereotype that women may not be as competent as men, which is demonstrated by clients asking about her credentials. She sees this as a "don't trust" message, which she feels is stronger with male clients. She feels that establishing a contract identifying therapy goals helps alleviate expectations becoming an issue in therapy. The life experiences she feels male clients expect her not to understand include: the male role as a provider and father, "being out in the work world", and male sexuality, i.e., that a man is expected to be the aggressor.

Therapist No. 7 is a 32 year old psychiatrist who spends $33 \%$ of her time in therapy, of which $2 / 3$ is spent with individuals, couples, 
and families, and $1 / 3$ is spent in groups. She feels that what happens to her with male clients in terms of behavior and expectations reflects her own growth as a woman and a therapist. Initially she was more motherly, i.e., taking care of clients rather than confronting them and challenging them. As she became more comfortable with her own sexuality and strengths as a woman and skilled and experienced as a therapist, she gained more freedom in allowing her clients to express a wide range of feelings and behaviors in therapy. She states that she does not know what male clients expect of her, but she knows what she could expect of herself, i.e., she feels she can be confrontive and strong or soft and nurturing, depending on the situation. On the life experience statement, she feels male clients expect her to understand their life experiences with the possible exception of men who have problems with anger towards women and sexual problems.

In summary there were trends that became apparent from these interviews. It appeared that men may feel more competitive working with a male therapist than with a female therapist, possibly because female therapists seem less threatening in a helping situation. The second trend was that as women became more experienced and assured as therapists and more comfortable with themselves as women, client expectations became less of an issue. They seem to find themselves playing the "mother role" less and becoming more confrontive and assertive with clients. Thirdly, it seemed that the life experiences that male clients expect female therapists to have a hard time understanding clustered around the stereotypic role of men having to "be strong." Examples cited that support this include the pressures of the breadwinner role, 
the role of father, the role of aggressor in sexual situations, the strong prohibition on the expression of emotions and the expectations that men have to be strong, capable, self-sufficient, and controlled.

In the closed-ended section of the interview schedule, each female therapist was asked to respond to the list of male client expectations these researchers developed from the conference (see page 15 or a copy of the interview schedule). Two statements were presented for each expectation. For example, on the expectation dealing with manipulation, the first statement was: "male clients expect you as a female therapist to be easily manipulated", and the second statement was, "male clients expect a male therapist to be easily manipulated." On the first statement, each therapist responded to a five point scale ranging from strongly agree to strongly disagree. Using the same scale on the second statement, she was asked to project male therapist experience. They were also asked to give examples whenever possible, especially on the expectation dealing with female therapist's ability to understand male client life experiences. The last question in this section asked whether the female therapist has had experience working with a male cotherapist, which might give the female therapist first-hand knowledge of client's responses to therapists of different sexes.

The results of the close-ended part of the interview schedule was determined by totaling each therapist's responses to each expectation; this included their responses to statements regarding female therapists and their projected responses to statements regarding male therapists. These results became the hypotheses for this study. The responses were divided into three categories: (1) therapy-related expectations; (2) 
sex-related expectations; and (3) undetermined expectations. When a majority of responses were the same for statements regarding male and female therapists on any one expectation, that expectation was classified as a therapy-related expectation, i.e, an expectation clients have of therapists in general. Sex-related expectations, i.e., expectations that differ due to the sex of the therapist, were determined to exist when the majority of responses to statements regarding female therapists were opposite the majority of responses to statements regarding male therapists. Undetermined expectations included those that were not clearly sex-related or therapy-related, however, they did have a tendency toward one or the other.

The results of this close-ended section and subsequent hypotheses for this study were:

1. That both male and female therapists are expected to be competent, sympathetic, logical, capable of understanding emotions (therapy-related expectations).

2. That female therapists are not expected to understand male client life experiences (sex-related expectations).

3. That there is a tendency that female therapists are expected to be less confrontive and more easily manipulated;

that there is a tendency that both male and female therapists are expected to be assertive, nurturing, and judgmental (undetermined expectations).

EVALUATION

Because the information in this chapter was gathered from a variety of sources, it tended to be subjective and therefore needs to be evaluated for its values and its biases. The conference provided stim- 
ulating ideas which helped to identify specific expectations clients may have of female therapists. In reviewing the validity of this information, it seems important to look at the following considerations. First, because the participants were representing a wide range of helping services, the content of their discussion did not necessarily apply to the therapeutic situation. Secondly, the expectations that were generated were expectations that both male and female clients might hold of female therapists. Thirdly, there was a momentum effect resulting from participants' emotional investment in the topic that mushroomed as ideas were generated. Each participant shared one or two specific expectations which appeared to be selected incidents in her total experience. Combining all participants' responses presented an unrealistic picture of client expectations of female therapists.

The philosophy used in formulating the questionnaire for female therapists' interviews was derived from this conference. It was not until after the interviews with female therapists that the biases, subjectivity, and incompleteness of this information became apparent. A number of limitations in the interview schedule seemed to result directly from this. The first 1 imitation was that the therapists were asked to use projection in responding to the questions. Because they speculated about male client and male therapists' experiences, this information may be distorted, or at least inaccurate. Therapists were also confused by being asked to project male client expectations prior to therapy based on behaviors and activities they observed during therapy. In addition, it became clear that the way the questions were worded conveyed a bias. It was pointed out by one therapist that the questions 
seemed to portray a view of female therapists "being taken advantage of." She saw the wording of the questions reflecting a sex-role stereotype image of women. Another limitation was that the questions asked did not allow for a variety of theoretical frameworks which influenced the responses of the therapists. For example, a therapist operating from a non-directive framework did not put the same value on assertion and confrontation as did a therapist operating from a more directive framework.

Furthermore, these researchers, in asking the questions, did not consistently clarify with the therapists their understanding of each expectation. The information was based on personal experience and was subjective in nature; thus, it applies to only these seven therapists and cannot be generalized.

However, the interviews with female therapists were valuable for a number of reasons. The information provided a framework and basis for an evaluation of the expectations identified at the conference. As a result, a more realistic perspective of client expectations was developed. The open-ended section of the interview schedule seemed effective in generating new ideas regarding expectations. The therapists also provided a number of specific examples, especially on the life experience statement, which will be beneficial later in this study. An interesting observation was that the therapists interviewed seemed to fall on a continuum. One end included younger, less experienced therapists who found their femaleness to be more of an issue in therapy. The opposite end included female therapists who were more experienced and whose personal integration included their femaleness and their role of therapist, thus making it less of an issue in therapy. 
Finally, it is important to comment on the purpose of the hypotheses for this study. The hypotheses are based only on the conference and the close-ended part of the questionnaire. Thus, the hypotheses of this study indicate trends or guidelines to be explored, rather than statements to be proved or disproved. This is appropriate because of the exploratory nature of this study.

It was decided to alter the expectation categories which formed the hypotheses. Based on information from the female therapist, the expectations that a therapist would be logical was unanimously seen as a therapy-related expectation, and therefore was not a meaningful category to consider. Because of the similarity in the way confrontation and assertiveness were defined for this study, it was decided to combine these categories under the heading of assertion. Because the expectation of judgmental was not clearly defined in the female therapist interviews, it was decided to study the expectation that a therapist will be non-judgmental rather than judgmental. Thus, the revised hypotheses used for the development of the male client questionnaire included:

1. That both male and female therapists are expected to be competent, sympathetic, capable of understanding emotions (therapy-related expectations).

2. That female therapists are not expected to understand male client life experiences (sex-related expectations).

3. That there is a tendency that female therapists are expected to be more easily manipulated; and 
that there is a tendency that both male and female therapists are expected to be assertive, nurturing, and non-judgmental (undetermined expectations). 
CHAPTER IV

METHODOLOGY

This chapter will describe the methodology used in this study. Initially the research design will be described. In addition, this chapter defines the expectation categories and describes the development of the questionnaire. It will also include a description of the sample, method for collecting data, and the kind of data analysis to be used.

\section{RESEARCH DESIGN}

To measure male client expectations of female therapists, a questionnaire will be developed and administered to actual clients. To achieve the purpose of this study as to whether the sex of the therapist is a variable in client expectations, a $2 \times 2$ design will be developed. The first part of the design is accomplished by writing half of the questionnaires with the therapist as female ("She"), and half of the questionnaires with the therapist as male ("He"). This constitutes what will be referred to as the male and female forms of the questionnaire. The second part of the design is accomplished by giving the questionnaire to male and female clients. Half of the male clients will respond to the male form of the questionnaire and half will respond to the female form of the questionnaire. Similarly, half of the female clients will respond to the male form and half to the female form of the questionnaire. The resulting four categories are: 


\begin{tabular}{l|c|c|}
\multicolumn{1}{c}{} & \multicolumn{1}{c}{$\begin{array}{c}\text { Female } \\
\text { Therapist }\end{array}$} & \multicolumn{1}{c}{$\begin{array}{c}\text { Male } \\
\text { Therapist }\end{array}$} \\
\cline { 2 - 3 } $\begin{array}{l}\text { Female } \\
\text { Client } \\
\text { Male } \\
\text { Client }\end{array}$ & female/female & female/male \\
\cline { 2 - 3 } & male/female & male/male \\
\hline
\end{tabular}

The rationale for using two forms of this questionnaire is to measure the influence of the sex of the therapist. The rationale for giving the questionnaire to both male and female clients is to compare male and female expectations, thus helping identify those expectations that may be unique to male clients.

DEFINITION OF TERMS

The following section defines the expectation categories on which the questionnaire is based. These definitions incorporate both descriptions used by Spilken et al. (1969) in "Personality Characteristics of Therapists", and these researchers' own understanding of what these terms mean.

Competence. The expectation of competence is defined as the client perceiving the therapist to be knowledgeable, believing in and knowing what he or she is doing, and appearing at ease, comfortable, and confident (Spilken).

Assertiveness. The expectation of assertiveness is defined as the client perceiving the therapist as appropriately providing structure, guidance, and limit setting (Spilken), and being active and straightforward. 
Sympathetic. The expectation of being sympathetic is defined as the client perceiving the therapist as having an emotional awareness of how the client feels and the therapist cormunicating his or her alliance with the client, but not totally identifying with him (Spilken). This quality as defined here is synonymous with empathy.

Nurturing. The expectation of nurturance is defined as the client perceiving the therapist as reassuring, encouraging, and promoting growth.

Non-judgmental. The expectation of a therapist being non-judgmental is defined as the client perceiving the therapist as showing appreciation and acceptance of the client's individual worth and uniqueness, and as being unconditionally accepting.

Easily manipulated. The expectation that a therapist will be easily manipulated is defined as the client perceiving the therapist as naive and trusting, and too easily convinced.

Understanding emotions. The expectation that a therapist will be able to understand emotions is defined as the client perceiving the therapist as aware and accepting of his feelings, and respecting individualized expression of his feelings.

Life experiences. This expectation deals with the notion that male clients may perceive a female therapist as having difficulty understanding certain life experiences. The ones included in this study were: the expectation that a man must support a family, the experience of being a father, military experiences, problems in relationships with women, and sexual concerns. 
DEVELOPMENT OF THE QUESTIONNAIRE

To gather information on the trends suggested by the hypotheses, a questionnare was developed for clients. The statements comprising the questionnaire were based on the eight expectation categories previously defined. A minimum of five statements, which described behaviors representing that expectation, were developed for each category. For example, the expectation of competence was described by this statement:

She will give advice when it is appropriate.

Furthermore, each category contained an equal number of expectations stated in a positive and negative form. Examples from the easily manipulated category are:

She can recognize if I am not being totally honest. She can be swayed by my behavior.

There were two reasons for making an equal number of positive and negative statements. One was to avoid portraying a sexual stereotyped bias of females. The second was to allow thoughtful consideration of each statement, thus alleviating a patterned response.

Questionnaire Format. The format of the questionnaire can be divided into three sections: the introductory letter, the body of the questionnaire, and the demographic information.

The introductory letter explained who the researchers were and what the information would be used for, assured the respondents of confidentiality, and encouraged their cooperation. 
The instructions to the body of the questionnaire asked the respondents to anticipate their contact with a therapist. One-half of the questionnaires referred to the therapist as female and one-half of them referred to the therapist as male. Respondents were asked to project their expectations of the therapist and respond accordingly to the statements on a five-point scale. The scale ranged from "strongly agree with this expectation" to "strongly disagree with this expectation." The final format included thirty-four statements, randomly arranged to mix expectation categories.

The primary purpose of the demographic information was to describe the respondents as to age, sex, year in school, reason for coming to the counseling center, and questions regarding prior counseling experience. In reference to the last item, this information will be useful in assessing whether current expectations differ for those who have had prior counseling as compared to those who have not.

Pre-Test. Both the male and female forms of the questionnaire were given to nine men and four women who were not actual clients. A number of changes were made on the basis of information received in the pre-test. Feedback on specific statements was helpful in assuring that the intended meaning of the statements was understood and was useful in clarifying ambiguous questions. A number of statements elicited at least four "no opinion" responses from the thirteen respondents. Because these undifferentiated responses were of little value, most of these statements were reworded and some were deleted. It also became apparent that it was necessary to assure that clients were using expectations as the basis for their responses. Therefore, the wording of the 
instructions was changed to emphasize expectations and the response scale was expanded from "strongly agree" to "strongly agree with this expectation."

Although all respondents were able to complete the questionnaire in ten minutes or less, the number of questions made the instrument appear long. Another consideration that affected the decision to reduce the number of questions was that the questions in the sympathetic expectation category were vague and difficult to differentiate from questions in the other expectation categories, such as non-judgmental and understanding emotions. Therefore, the sympathetic category was eliminated, reducing the total number of expectation categories to seven.

\section{SAMPLING}

The Agency. In seeking an agency that would allow access to actual clients to whom the questionnaire would be given, it was decided to use an agency which served voluntary clients as opposed to clients who are pressured to seek counseling by external sources. The counseling center at Portland State University, Portland, Oregon, met this criteria. Other advantages of using the counseling center included its easy access to these researchers, and the center's interest and support of research endeavors. In addition, it seemed to provide a more homogeneous population in terms of age and education as compared to other mental health settings described by female therapists.

The three services that are provided for students at the counseling center are categorized as vocational testing and counseling, personal counseling, and educational counseling. 
The Sample. The respondents for this study included all new male and female clients initiating counseling between January 5, 1976, and Apri1 12, 1976. It was impossible to assure that all questionnaires would be completed and returned. The actual number of questionnaires unaccounted for were 4 out of a total of 108. It was the choice of these researchers to eliminate from this sample all responses in which the clients were exclusively seeking vocational counseling. This process resulted in 26 questionnaires being eliminated.

In addition, the sample was divided into two strata according to the sex of the client. This was achieved by creating two stacks of questionnaires at the counseling center; one for male clients and one for female clients. The sample was further stratified according to the sex of the therapist. This was accomplished by alternating male and female forms of the questionnaire in each stack described above. This method was designed to attempt to equalize the number of responses for each of the four categories.

\section{DATA COLLECTION}

To collect this data, each new client was given a questionnaire from the appropriate stack by the counseling center secretaries, along with the routine information sheet requested by the counseling center prior to the initial interview. Clients were asked to complete the questionnaire, place it in the envelope provided, and deposit it in the box provided on the counseling center desk. 
Totals of data collected

Total number of questionnaires distributed 108

Total number of questionnaires collected 104

Total number of vocational questionnaires

Total number returned, uncompleted $\quad 18$

Total number of questionnaires lost $\quad 4$

Total number of usable questionnaires $\quad 60$

of the 60 usable questionnaires, they fit into the $2 \times 2$ design in the following way:

TABLE I

TOTAL NUMBER OF QUESTIONNAIRES

OBTAINED PER CATEGORY

\begin{tabular}{|c|c|c|}
\hline & Female Therapist Forms & Male Therapist Forms \\
\hline $\begin{array}{l}\text { Female } \\
\text { Clients }\end{array}$ & 14 & 19 \\
\hline $\begin{array}{c}\text { Male } \\
\text { Clients }\end{array}$ & 12 & 15 \\
\hline
\end{tabular}

Vocational questionnaires were eliminated after they were filled out because this was more convenient for the office staff at the counseling center. However, this procedure affected the randomness for each of the four client response categories and accounted for some of the inequality in the total number of questionnaires obtained per category. 
DATA ANAL YSIS

In analyzing the data, it was decided to initially obtain means, standard deviations, and percentages on all statements and demographic questions to be used in comparing the four client response categories. Secondly, a discriminant function analysis was done on six expectation categories to obtain a $D^{2}$ value to be used in determining whether there was any significant difference between the four client response categories. 


\section{CHAPTER V}

\section{RESULTS}

This chapter will describe the sample based on demographic information obtained from the questionnaire. It will also include the statistical results completed on the expectation categories.

\section{DESCRIPTION OF THE SAMPLE}

This section includes tables on demographic variables and narrative comments.

\section{TABLE II}

MEAN AND STANDARD DEVIATION

OF. THE AGES OF

THE CLIENTS

\begin{tabular}{l|ll|ll}
\hline \hline \multicolumn{2}{c}{ Female Form } & \multicolumn{2}{c}{ Male Form } \\
\cline { 2 - 5 } $\begin{array}{l}\text { Female } \\
\text { Clients }\end{array}$ & $\bar{x}$ & 23.38 & $\bar{x}$ & 23.52 \\
& $\sigma$ & 2.7237 & $\sigma$ & 4.3763 \\
\cline { 2 - 5 } $\begin{array}{l}\text { Male } \\
\text { Clients }\end{array}$ & $\bar{x}$ & 23.58 & $\bar{x}$ & 24.13 \\
& $\sigma$ & 4.2737 & $\sigma$ & 3.8147 \\
\hline
\end{tabular}

The mean age of clients in all four categories was similar, reflecting a homogeneous sample. However, the mean age appears to be old- 
er than might be anticipated in an average university population.

The range of ages for female clients responding to female form of the questionnaire was 19-27 years. The range for female clients responding to the male form of the questionnaire was 19-36 years. The range for male clients responding to the female form of the questionnaire was 19-31 years. The range for male clients responding to the male form of the questionnaire was $20-30$ years.

TABLE III

FREQUENCY OF CLIENTS

ACCORDING TO YEAR

IN SCHOOL

\begin{tabular}{|c|c|c|c|c|}
\hline & \multicolumn{2}{|c|}{$\begin{array}{l}\text { Female Clients } \\
\text { Responding to: }\end{array}$} & \multicolumn{2}{|c|}{$\begin{array}{l}\text { Male Clients } \\
\text { Responding to: }\end{array}$} \\
\hline \multirow{3}{*}{$\overline{8}_{\frac{0}{4}}^{1} 2$} & Female Form & Male Form & Female Form & Male Form \\
\hline & 3 & 1 & 0 & 3 \\
\hline & 0 & 3 & 3 & 2 \\
\hline \multirow{3}{*}{ 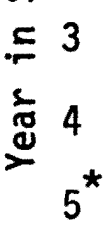 } & 3 & 9 & 6 & 0 \\
\hline & 4 & 4 & 1 & 7 \\
\hline & 5 & 2 & 2 & 3 \\
\hline$T$ & 15 & 19 & 12 & 15 \\
\hline $\bar{x}$ & 3.50 & 3.15 & 3.16 & 3.33 \\
\hline
\end{tabular}

* Graduate students.

The mean year in school is similar in all four categories, reflecting a homogeneous sample. 
TABLE IV

PERCENTAGE AND FREQUENCY OF CLIENTS

WITH PRIOR COUNSELING EXPERIENCE

Female Clients

Responding to:
Male Clients

Responding to:

\begin{tabular}{|c|c|c|c|c|c|c|c|c|}
\hline & \multicolumn{2}{|c|}{ Female Form } & \multicolumn{2}{|c|}{ Male Form } & \multicolumn{2}{|c|}{ Female Form } & \multicolumn{2}{|c|}{ Male Form } \\
\hline \multirow{3}{*}{ 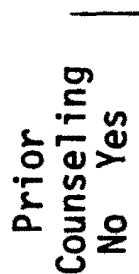 } & $f$ & $\%$ & $f$ & $\%$ & $f$ & $\%$ & $f$ & $\%$ \\
\hline & 8 & 57 & 13 & 68 & 2 & 17 & 4 & 27 \\
\hline & 6 & 43 & 6 & 32 & 10 & 83 & 11 & 73 \\
\hline$T$ & 14 & $100 \%$ & 19 & $100 \%$ & 12 & $100 \%$ & 15 & $100 \%$ \\
\hline
\end{tabular}

More females than males in this sample have had prior counseling experience. The percentages of all females who have had prior counseling was found to be 63 percent. The percentage for all males was 22 percent. It is interesting to note that most male and female clients had their prior counseling experience before 1975 (20 clients). Only four clients had received counseling during 1975 and there were three "no responses." Prior counseling experience was generally for personal reasons, with only a few seeking educational or vocational counseling. 
TABLE V

SEX OF THERAPIST IN

PRIOR COUNSELING

EXPERIENCE

\begin{tabular}{|c|c|c|c|c|c|c|c|}
\hline \multirow[b]{3}{*}{$\begin{array}{l}\text { Female } \\
\text { Clients }\end{array}$} & \multicolumn{2}{|c|}{$\begin{array}{c}\text { Female } \\
\text { Therapist }\end{array}$} & \multicolumn{2}{|c|}{$\begin{array}{c}\text { Male } \\
\text { Therapist }\end{array}$} & \multicolumn{2}{|c|}{$\begin{array}{c}\text { No } \\
\text { Preference }\end{array}$} & Totals \\
\hline & & $\%$ & & & $\bar{f}$ & $\%$ & $f \%$ \\
\hline & 11 & 33 & 2 & 6 & 19 & 58 & $3297^{*}$ \\
\hline $\begin{array}{c}\text { Male } \\
\text { Clients }\end{array}$ & 3 & 11 & 4 & 5 & 20 & 74 & $27 \quad 100$ \\
\hline
\end{tabular}

Generally, both male and female clients have seen more male counselors than female counselors. It should be noted that prior counseling experience may have an important effect on counseling expectations.

TABLE VI

SEX OF THERAPIST PREFERRED FOR

CURRENT COUNSELING

EXPERIENCE

\begin{tabular}{|c|c|c|c|c|c|c|c|c|c|c|}
\hline \multirow[b]{3}{*}{$\begin{array}{l}\text { Female } \\
\text { Clients }\end{array}$} & \multicolumn{2}{|c|}{$\begin{array}{l}\text { Female } \\
\text { Therapist }\end{array}$} & \multicolumn{2}{|c|}{$\begin{array}{c}\text { Male } \\
\text { Therapist }\end{array}$} & \multicolumn{2}{|c|}{ Both } & \multicolumn{2}{|c|}{$\begin{array}{c}\text { No Prior } \\
\text { Counseling }\end{array}$} & \multirow{2}{*}{\multicolumn{2}{|c|}{ Totals }} \\
\hline & & $\%$ & $f$ & $\%$ & & $\%$ & $f$ & $\%$ & & \\
\hline & 5 & 15 & 11 & 33 & 5 & 15 & 12 & 37 & 33 & 100 \\
\hline $\begin{array}{l}\text { Male } \\
\text { Clients }\end{array}$ & 1 & 4 & 4 & 15 & 1 & 4 & 21 & 77 & 27 & 100 \\
\hline
\end{tabular}


Most clients, both male and female, had no preference regarding the sex of their therapists. Of those having preferences, the trend was to prefer a therapist of the same sex. The percentage of female clients preferring a female therapist was greater than the percentage of males preferring a male therapist.

\section{RESULTS ACCORDING TO EXPECTATION CATEGORIES}

This section includes tables on expectation categories and narrative comments. (See methodology for operational definitions of expectation categories.) The results of the discriminant function analys is yielded no significant difference for all the expectation categories. However, trends that may exist will be examined in light of the mean responses to statements on the questionnaire.

The means recorded on Tables \#8-14 are based on a scale of 1 to 5 . On this scale, means that are closer to one indicate a more strongly held expectation of the therapist and means that are closer to five indicate a less strongly held expectation of the therapist. In suggesting general trends, the means for each statement within a client response category were averaged to yield a mean for that response category, which will be referred to as a group mean. General trends for each expectation category are then established by where the group means for all four client response categories fall on the 1 to 5 scale.

To suggest unusual trends within an expectation category, the group means of the four client response categories will be compared. A similarity in group means suggests that all clients hold that expectation of male and female therapists to a similar degree. A difference in group 
means suggests that the degree to which an expectation is held may differ due to the sex of the client or the sex of the therapist as reflected in the client response categories. Because the focus of this study is male client expectations of female therapists, that category will be compared to the other three response categories.

\section{TABLE VII}

MEANS FOR ITEMS WITHIN THE NURTURING CATEGORY

\begin{tabular}{|c|c|c|c|c|}
\hline \multicolumn{5}{|c|}{ Client Response Categories } \\
\hline \multirow{3}{*}{ 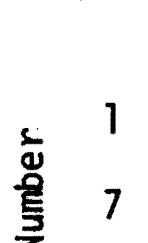 } & Female/Female & Female/Male & Male/Female & Male/Male \\
\hline & 1.50 & 1.74 & 1.75 & 1.67 \\
\hline & 1.50 & 1.89 & 2.16 & 1.60 \\
\hline & 2.07 & 2.00 & 2.91 & 2.20 \\
\hline & 2.00 & 2.05 & 2.41 & 2.20 \\
\hline & 1.85 & 1.73 & 2.25 & 1.86 \\
\hline $\begin{array}{l}\text { Group } \\
\text { Mean }\end{array}$ & 1.78 & 1.88 & 2.30 & 1.90 \\
\hline
\end{tabular}

In Table VII, a rating of one represents that clients expect therapists to have appropriate qualities of nurturing. A rating of five represents less appropriate qualities of nurturance.

When using the discriminant analysis, it was found that there is no significant difference between the four client response categories. To be significant, a $D^{2}$ value must exceed 21.026 . In this category, the $D^{2}$ value was 20.8590 . 
The general trend suggests that all clients expect therapists to display appropriate qualities of nurturance. However, the male/female response category suggests that male clients may expect female therapists to be less appropriately nurturing as represented by the difference in that category's group mean as compared to the other three categories' group means.

TABLE VIII

MEANS OF THE MANIPULATION CATEGORY

\begin{tabular}{|c|c|c|c|c|}
\hline \multicolumn{5}{|c|}{ Client Response Categories } \\
\hline \multirow{6}{*}{ 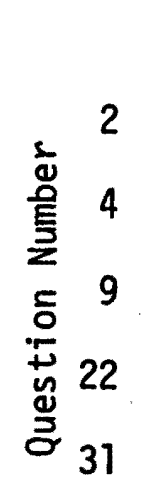 } & Female/Female & Female/Male & Male/Female & Male/Male \\
\hline & 2.21 & 2.47 & 2.91 & 2.60 \\
\hline & 2.71 & 2.32 & 2.75 & 2.50 \\
\hline & 2.50 & 2.79 & 3.00 & 3.00 \\
\hline & 2.36 & 2.26 & 3.08 & 2.87 \\
\hline & 2.50 & 2.42 & 2.33 & 2.60 \\
\hline $\begin{array}{l}\text { Group } \\
\text { Mean }\end{array}$ & 2.46 & 2.45 & 2.81 & 2.71 \\
\hline
\end{tabular}

In the above Table, a rating of one represents the client's expectation that the therapist will not be easily manipulated. A rating of five represents that the therapist will be easily manipulated.

The discriminant analys is indicates no significant difference between the four client response categories. The $D^{2}$ value for this category is 15.23885 .

The general trend in this category sugges ts that all clients ex- 
pect therapists not to be easily manipulated; however, the group means based on the 1 to 5 scale are closer to five than they are for any other expectation category. In comparing the four client response categories, the group mean for the male/female category is the closest to five, suggesting a trend that male clients may expect a female therapist to be more easily manipulated.

$D^{2}$ values will not be included on Tables \#10-14 because they are of less interest than those previously mentioned.

TABLE IX

MEANS OF THE ASSERTIVENESS CATEGORY

\begin{tabular}{|c|c|c|c|c|}
\hline \multicolumn{5}{|c|}{ Client Response Categories } \\
\hline \multirow{6}{*}{ 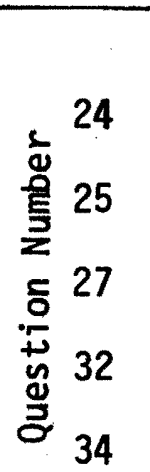 } & Female/Female & Female/Male & Male/Female & Male/MaTe \\
\hline & 2.92 & 2.63 & 2.50 & 2.60 \\
\hline & 2.21 & 2.42 & 2.67 & 2.33 \\
\hline & 2.50 & 2.68 & 3.00 & 2.67 \\
\hline & 1.78 & 1.73 & 2.08 & 1.86 \\
\hline & 1.64 & 1.78 & 2.00 & 1.80 \\
\hline $\begin{array}{l}\text { Group } \\
\text { Mean }\end{array}$ & 2.21 & 2.28 & 2.45 & 2.25 \\
\hline
\end{tabular}

In Table IX, a rating of one represents the expectation that the therapist will be appropriately assertive. A rating of five represents that the therapist will be non-assertive.

The general trend in this category suggests that all clients expect therapists to be appropriately assertive. However, the group means 
on the 1 to 5 scale are second to nurturing in being closer to five. It is interesting to note that the group means for the male/female response category is closer to five than the means for the other three categories.

TABLE $X$

MEANS OF THE NON-JUDGMENTAL CATEGORY

\begin{tabular}{|c|c|c|c|c|}
\hline \multicolumn{5}{|c|}{ Client Response Categories } \\
\hline \multirow{5}{*}{ 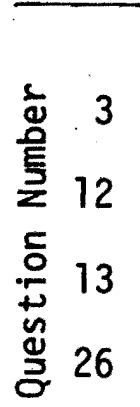 } & Female/Female & Female/Male & Male/Female & Male/Male \\
\hline & 1.86 & 1.84 & 2.00 & 1.60 \\
\hline & $1: 71$ & 1.74 & 1.64 & 1.73 \\
\hline & 1.67 & 1.63 & 2.09 & 1.93 \\
\hline & 2.07 & 2.05 & 2.41 & 2.13 \\
\hline $\begin{array}{l}\text { Group } \\
\text { Mean }\end{array}$ & 1.83 & 1.82 & 2.04 & 1.85 \\
\hline
\end{tabular}

In the above Table, a rating of one represents the expectation that the therapist will be non-judgmental, i.e., unconditionally accepting. A rating of five represents that the therapist will be judgmental, i.e., less unconditionally accepting.

The general trend in this category suggests that all clients expect therapists to be non-judgmental. It is interesting to note that the group mean for the male/female response category is closer to five than the group means for the other three categories. 
TABLE XI

MEANS OF THE UNDERSTANDING EMOTIONS CATEGORY

\begin{tabular}{|c|c|c|c|c|}
\hline \multicolumn{5}{|c|}{ Client Response Categories } \\
\hline \multirow{5}{*}{ 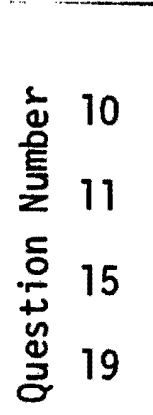 } & Female/Female & Female/Male & Male/Female & Male/Male \\
\hline & 2.21 & 2.10 & 2.33 & 2.20 \\
\hline & 1.71 & 1.84 & 1.75 & 1.73 \\
\hline & 1.64 & 2.00 & 1.91 & 1.73 \\
\hline & 2.86 & 2.11 & 2.25 & 2.07 \\
\hline $\begin{array}{l}\text { Group } \\
\text { Mean }\end{array}$ & 2.11 & 2.01 & 2.06 & 1.93 \\
\hline
\end{tabular}

In this Table, a rating of one represents the expectation that a therapist will understand emotions and the expression of emotions. A rating of five represents that a therapist will have less understanding of emotions.

A general trend seems to be that all clients expect therapists to understand emotions. There are no unusual trends among the client response categories. 
TABLE XII

MEANS OF THE COMPETENCE CATEGORY

\section{Client Response Category}

\begin{tabular}{|c|c|c|c|c|}
\hline \multirow{5}{*}{ 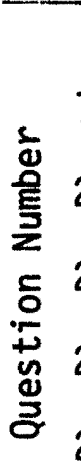 } & Female/Female & Female/Male & Male/Femále & Male/Male \\
\hline & 2.00 & 2.10 & 2.18 & 2.06 \\
\hline & 2.35 & 2.21 & 1.91 & $1: 93$ \\
\hline & 2.21 & 2.26 & 2.33 & 2.13 \\
\hline & 1.93 & 2.05 & 2.00 & 2.33 \\
\hline \% 29 & 2.50 & -2.42 & 2.00 & 2.53 \\
\hline $\begin{array}{l}\text { Group } \\
\text { Mean }\end{array}$ & 2.20 & 2.21 & 2.08 & 2.20 \\
\hline
\end{tabular}

In Table XII, a rating of one represents the expectation that the therapist will be competent. A rating of five represents that the therapist will be less competent.

The general trend appears to indicate that all clients expect therapists to be competent. It is interesting to note that the group mean for the male/female response category is closer to one than the group means for the other three categories. 
TABLE XIII

MEANS OF THE LIFE EXPERIENCE CATEGORY

\begin{tabular}{|c|c|c|c|c|}
\hline \multicolumn{5}{|c|}{ Client Response Categories } \\
\hline & $\begin{array}{l}\text { Female/ } \\
\text { Female } \\
\end{array}$ & $\begin{array}{l}\text { Female/ } \\
\text { Male } \\
\end{array}$ & $\begin{array}{l}\text { Malel } \\
\text { Female }\end{array}$ & $\begin{array}{l}\text { Male/ } \\
\text { Male }\end{array}$ \\
\hline Military & & & 2.45 & 2.36 \\
\hline $\begin{array}{c}23 \\
\text { Father }\end{array}$ & & & 2.55 & 2.40 \\
\hline $\begin{array}{l}8 \\
\text { Opposite Sex }\end{array}$ & 1.71 & 2.21 & 2.08 & 1.86 \\
\hline $\begin{array}{c}30 \\
\text { Sexual Concerns }\end{array}$ & 1.93 & 2.21 & 2.00 & 2.20 \\
\hline$\stackrel{32}{\text { Support Family }}$ & 2.07 & 2.50 & 2.00 & 2.20 \\
\hline
\end{tabular}

Due to the nature of the statements in this category, a discriminant analysis was not used. Each of the five statements will be considered individually. The mean for each client response category will be compared for each statement. In this Table, a rating of one represents that a therapist will be expected to understand the client's life experiences. A rating of five represents that they will be less likely to understand.

On the statements regarding military experience and the role of being a father, the female clients' responses have been excluded because the statements did not apply to females and because of lack of response by female clients to these statements. On the military statement, it 
seems to be expected by male clients that both male and female therapists can understand what military experience is like. The means of the two male client response categories are similar. On the statement regarding the role of being a father, male clients seem to expect that both male and female therapists can understand being in that role. The means of the two male client response categories are similar.

The following three statements are compared with female client responses included. On the statements regarding problems with the opposite sex, sexual concerns, and the role of family supporter, the general trend suggests that all clients expect all therapists to be understanding. The extent to which clients seem to view therapists as understanding varies among the client response categories. On the statement regarding problems with the opposite sex, both male and female clients may tend to expect therapists of the same sex to be more understanding than therapists of the opposite sex. Regarding sexual concerns, it is interesting to note that both male and female clients may tend to expect female therapists to be more understanding than male therapists. On the statement regarding the role of family supporter, male and female clients appear to expect female therapists to be more understanding than male therapists. 


\section{CHAPTER VI}

\section{CONCLUSIONS AND IMPLICATIONS}

This final chapter will describe conclusions regarding the general results, conclusions regarding the hypotheses, and implications for social work.

\section{CONCLUSIONS REGARDING GENERAL RESULTS}

The major conclusion of this study is that there is no significant difference among the four client response categories. This section will examine possible reasons for this conclusion by taking into account the purpose of the study, the instrument, and the sample.

The original purpose of this study was exploratory in nature; to establish whether expectations of therapists existed and differed on the basis of the sex of the client or the sex of the therapist. To accomplish this purpose, an instrument was developed and administered to measure these expectations with the hope of obtaining data which would allow for significant conclusions. In retrospect, it has become apparent that in actuality three research processes were being attempted. The logical sequence to follow would have been the generation of ideas, development and validation of an instrument, and the administration of the instrument to obtain meaningful statistical results. Because each of these steps could have been a study in and of itself, and because these researchers attempted to do all three, the purpose of this study was not fully accomplished. It was premature to assume that statistical 
significant results could be achieved without fully generating ideas and validating an instrument. This may explain why no significant differences were found in this study.

There are several reasons why the instrument developed for this study was not as useful as expected. To begin, in terms of questionnaire format, the instrument failed to measure the existence of expectations; instead it assumed that they existed and measured the degree to which they were held by clients. Perhaps a different questionnaire format focusing on the existence of expectations would have better achieved this purpose. Secondly, it is impossible to positively conclude that the instrument, i.e., wording of statements and directions, yielded responses that measure sex differences implied in the male and female forms of the questionnaire.

This instrument is not valid or reliable for a number of reasons. It is not possible to know if statements represented the expectation categories they were designed to measure. A factor analysis would have provided some statistical indication as to whether statements were representing what they were intended to measure; however, due to a time limit, this was not possible. Also, a more extensive pre-test and a more thorough analysis of the results would have helped to validate the instrument. Finally, there was no effort to compare this instrument with any other similar validated instruments.

A number of factors regarding the sample may have contributed to the major conclusion of this study. Although the sample for this study appears homogeneous, there was no way to know what other variables or characteristics of the sample may have influenced client responses. For 
example, as discussed in the literature review, in an article by Tan (1967), race and nationality have a significant impact on expectations. Also, socio-economic class might be another variable to consider. Secondly, the clients' level of psycho-social development probably influenced how they viewed characteristics attributed to therapists as they responded to the questionnaire. For example, if a client was striving to be independent, he might have rejected the nurturing qualities implied in the statements.

After obtaining the data, it became apparent that there were two factors relating to the sample that may have influenced the results of this study. First, there were unequal numbers of responses for each client response category. Secondly, more female clients than male clients had had prior counseling. No doubt this prior experience provided a framework on which their current expectations were based. Many male clients did not have past counseling experience as a bases for responding to the statements. It is impossible to know what bases these male clients used for their responses. Kadushin (1958) and Patterson (1958) suggests that if a client does not know how to be a client, he or she will rely on past similar encounters. Thus, male clients responding to female therapists may have used past encounters with other females or professionals as a frame of reference.

\section{CONCLUSIONS REGARDING THE HYPOTHESES}

This section will compare the original hypotheses with the results of the questionnaire to determine if the results support the hypotheses. It will also offer possible reasons why clients responded as they did to 
specific expectation categories. The following reasons are in addition to those previously stated as to why the results showed no statistical significant difference. Because of the way the hypotheses are used and stated in this study, it must be kept in mind that the hypotheses for the therapy-related expectations are supported when there is no significant difference.

The first hypothes is identified therapy-related expectations; that both male and female therapists are expected to be competent, capable of understanding emotions, and sympathetic. As explained in the methodology, the expectation category of sympathetic was excluded from the questionnaire. For the other two expectation categories, the results of the discriminant analysis and the comparison of the group means supported this hypothesis since in a therapy-related expectation, one would not expect to find a significant difference. In light of the fact that the understanding emotions category focused on the expression of emotion, it is interesting to corrsider that the clients' willingness to express emotions may have been an influential factor in their responses.

The second hypothesis was defined as a sex-related expectation; that female therapists are not expected to understand male life experiences. The comparison of the group means on each individual statement for the four client response categories did not support the hypothesis. It is strongly felt that this category did not measure what it was intended to measure. After it was decided to give the questionnaire to female clients as well' as male clients, it was necessary to reword the life experience statements which weakened that category's ability to reflect unique male life experiences. 
The third hypothesis, dealing with undetermined expectations, was divided into two parts -- those with a tendency to be sex-related and those with a tendency to be therapy-related.

The hypothes is for the manipulation category suggested a sex-related influence, that female therapists are expected to be more easily manipulated. The discriminant analys is showed no significant difference. However, the comparison of group means indicated a trend that supported the hypothesis. Because manipulation statements inferred that clients may use manipulating behaviors, it should be considered that $\mathrm{client}$ responses may have been influenced by whether or not clients saw themselves using those behaviors. This may explain why the group means were closer to 5 on the 1 to 5 scale.

The hypothes is for the assertive, non-judgmental, and nurturing expectation categories suggested a therapy-related influence, that both male and female therapists are expected to have these three qualities. Regarding the assertive and the non-judgmental categories, there was no significant difference on the discriminant analysis, and the comparison of the group means was also supportive of the hypothesis. This was expected with a therapy-related expectation. The group means in the assertiveness category may have been influenced by the clients' possible uncertainty as to whether assertiveness is an appropriate quality for a therapist to display. As previously discussed in the Conceptual Framework, the non-directive approach to therapy does not value assertiveness as a therapist's quality. In reference to the nurturing expectation category, the discriminant analys is showed no significant difference, which is consistent with therapy-related expectations. In contrast, the 
comparison of the groups means indicated a trend that was not consistent with the hypothesis; group means for the male/female response category was noticeably closer to five than the group means for the other three client response categories. It appears that the expectation of nurturance comes closest to being influenced by the sex of the therapist or the sex of the client. Also, the $D^{2}$ value for this expectation category was strikingly close to a significant $D^{2}$ value. A significant $D^{2}$ value would have indicated that the sex of the client or the therapist was an influential factor on this expectation.

IMPLICATIONS

This section will discuss what implications this study has for practicing therapists and future research.

As supported in the Literature Review, because client expectations affect the outcome of therapy, it is important for therapists to be aware of their existence and their nature. While this study did not verify'the existence of expectations, if in fact the expectations studied did not exist, this instrument, in spite of its limitations, would have given a general indication of this. Client responses would have fallen closer to five, the "do not expect" end of the scale. Secondly, it is the belief of these researchers that had gross differences based on sex existed, this also would have been indicated by this instrument. In spite of the fact that this study did not conclude that sex influences expectations, these researchers appeal to therapists to recognize the impact client expectations do have on the therapeutic situation.

This study has a number of different implications for future re- 
search. Because this sample was taken from a University setting, it is difficult to generalize the results to other populations. First, it is likely the educational level of this sample may have an influence on the nature of expectations. Also, because this sample does not represent a cross-section of society, it is possible the race or socio-economic class are not proportionately represented. A third consideration is that the agency studied serves voluntary clients, as compared to an institutional setting where clients' circumstances are different. Because of the above reasons, these researchers feel that further studies on expectations need to be conducted in other therapeutic settings.

Because little research could be found on the topic of male client expectations of female therapists, one of the purposes of this study was to generate ideas for further research. One idea these researchers found fascinating evolved from the interviews with the female therapists. It appeared that the level of female therapists' personal and professional growth affected the expectations they felt clients held of them. The existence of this phenomenon would be an interesting topic to study. Additionally, female therapists consistently pointed out that they thought the area of male life experiences would be an expectation that would differ with the sex of the therapist. Because this study did not estabrish conclusive evidence in this area, it is felt that this is still an important area to be studied further.

Two aspects of this study are recommended when considering future research. When comparing four groups based on sexual pairings, the $2 \times 2$ design provides a structure which can yield data for firm comparisons and subsequent conclusions. The second aspect is the use of actual cli- 
ents, which provides more meaningful and applicable information than does hypothetical situations, and which was not found to be difficult to accomplish in this study.

This study establishes no conclusive evidence as to whether male and female therapists are perceived differently due to their sex. However, the constant fluidity of society's values and the changing roles of men and women demand periodic reappraisal of the impact these changes have on the social work profession and more specifically on the therapeutic encounter. 
Apfelbaum, D. Dimensions of Transference in Psychotherapy. Berkely: University of California Press, 1958.

Appel, V. H. "Client Expectancies About Counseling in a University Counseling Center." Paper read at Western Psychological Association, San Jose, California, Apri1 1960.

Bordin, Edward S. "Implications of Client Expectations for the Counseling Process." Journal of Counseling Psychology 2 (Spring 1955): $17-21$.

Boulware, Donald W. and Holmes, David S. "Preferences for Therapists and Related Expectancies." Journal of Consulting and Clinical Psychology 35 (October 1970): 269-277.

Brooks, Linda. "Interactive Effects of Sex and Self-Disclosure." Journal of Counseling Psychology 21 (November 1974): 469-474.

Broverman, Inge K. and Broverman, Donald M., Clarkson, Frank E., Rosenkrantz, Paul S., and Vogel, Susan R. "Sex Role Stereotypes and Clinical Judgment of Mental Health." Journal of Consulting and Clinical Psychology 34 (February 1970): 1-7.

"Sex Role Stereotypes: A Current Appraisal." Journal of Social Issues 28 (November 1972): 59-78.

Chance, Erika. Families in Treatment. New York: Basic Books, 1959.

Form, Arnold L. "Measurement of Student Attitudes Toward Counseling Services." Personnel and Guidance Journal 32 (October 1953): 84-87.

Fuller, Frances F. "Influences of Sex of Counselor and of Client on Expressions of Feelings." Journal of Counseling Psychology 10 (Spring 1963): 34-40.

"Preferences for Male and Female Counselors." Personnel and Guidance Journal 42 (January 1964): 463-467.

Gladstein, G. A. "Client Expectations, Counseling Experience, and Satisfaction." Journal of Counseling Psychology 16 (November 1969): $476-481$.

Goldstein, Arnold P. Therapist-Patient Expectancies in Psychotherapy. New York: The MacMillan Company, 1962. 
Grosz, Richard D. "Effect of Client Expectations on the Counseling Relationship." Personnel and Guidance Journal 48 (Apri1 1968): 797-799.

Holt, S. "Client's Image of Counselor." Master's thesis, State College of Washington, 1950.

Horton, Paul B. and Hunt, Chester L. Sociology. New York: McGraw-Hill Book Company, 1964.

Kadushin, Alfred. "Social Sex Roles and Initial Casework Interview." Mental Hygiene 42 (July 1958): 354-361.

Kelly, G. A. The Psychology of Personal Constructs. New York: W. W. Norton, 1955 .

Levy, J. R. and Iscoe, I. "On Selecting a Therapist: Age and Sex Choices of College Students." Unpublished Manuscript, University of Texas, 1963.

Lorr, Maurice. "Client Perceptions of Therapists." Journal of Consulting Psychology 29 (April 1965): 146-149.

Miller, Donna. "The Influence of the Patient's Sex on Clinical Judgment." Smith College Studies in Social Work 44 (February 1974): $89-100$.

Patterson, C. H. "Client Expectations and Social Conditioning." Personnel and Guidance Journal 37 (October 1958): 136-138

Pew, Mirian L., Speer, David C., and Williams, James. "Group Counseling for Offenders." Social Work 18 (January 1973): 74-79.

Schwartz, Mary C. "Importance of the Sex of Worker and Client." Social Work 19 (March 1974): 177-185.

Simon, William C. "Age, Sex, Title of the Therapists as Determinants of Patient's Preferences." Journal of Psychology 83 (January 1973): 145-149.

Sonne, Thomas R. and Goldman, Leo. "Preferences of Authoritarian and Equalitarian Personalities for Client-Centered and Ecclectic Counseling." Journal of Counseling Psychology 4 (Summer 1957): 129-135.

Spilken, Aron E., Jacobs, Martin A., Miller, James J., and Knitzer, Jane. "Personality Characteristics of Therapists: Description of Relevant Variables and Examination of Conscious Preferences." Journal of Consulting and Clinical Psychology 33 (June 1969): 317326. 
Tan, H. "Intercultural Study of Counselor Expectations." "Journal of Counseling Psychology 14 (March 1967): 122-130.

Thomas, Edwin, Polansky, Normal, and Kounin, Jacob. "The Expected Behavior of the Potentially Helpful Person." Human Relations 8 (1955): $165-174$. 


\section{APPENDIX}

\section{INTERVIEW SCHEDULE FOR FEMALE THERAPISTS}

I. Description of our project.

Our study is exploratory. We are attempting to find out if male clients have expectations of female therapists. If they do, we want to find out what they are and how they differ from what male clients expect from male therapists.

II. Background information on therapist.

III. Open-ended section.

We would like to get your current ideas, feelings, opinions on male client expectations of you as a female therapist. In answering the following questions, it would be helpful to us if you generalize, reflecting in general on your experiences with male clients. After answering the questions we will be asking for specific behaviors and activities you have experienced, which support your generalized opinions.

A. Do male clients have expectations of you as a female therapist?

If no - what do you base your answer on.

If yes - what are these expectations (be as specific as possible).

List expectations and have them explain them in terms of behaviors and activities. Summarize list.

B. Do you think these expectations differ from what male clients expect of male therapists?

C. If so, how do they differ? (Cover all expectations interviewee listed in Part A.)

IV. Specific expectations.

In June we attended a conference of female therapists. During one workshop of the conference, client expectations were discussed. In addition to those expectations discussed at the conference, we have identified a few. We would like you to respond to these expectations. By doing this, we will have a better idea if they are valid. 
Procedure: We will state two expectations. The first will identify your opinion as to what male clients, in general, expect of you as a female therapist. The second will identify your opinion on what male clients expect of male therapists on the same variable (projection).

You can respond to each statement by letting us know on a scale of 1 to 5 ( 1 is strongly agree and 5 is strongly disagree) what you think. We will also be asking for specific behaviors and activities you have experienced to support your opinion.

Probes:

manipulate for control in interview situation

Probes:

experiences with questionning qualifications, degrees, credentials, knowledgeable, know what you are doing

Probes:

direct, straightforward

Probes:

mothering, meeting needs

Probes: not to be put on the spot, less demanding that they look at and work on problems
A. Male clients expect you as a female therapist to be easily manipulated.

1. Scale.

2. Activities/behaviors.

Male clients expect a male therapist to be easily manipulated.

1. Scale.

2. Reasons - not that necessary.

B. Male clients do not expect you as a female therapist to be competent.

Male clients do not expect a male therapist to be competent.

C. Male clients expect you as a female therapist to be non-assertive.

Male clients expect a male therapist to be non-assertive.

D. Male clients expect you as a female therapist to be nurturing.

Male clients expect a male therapist to be nurturing.

E. Male clients expect you as a female therapist to be non-confrontive.

Male clients expect a male therapist to be non-confrontive. 
Probes:

overidentify, feel

sorry for, pity

Probes:

rational, reasonable

Probes:

if agree, what areas

Probes:

unconditionally

accepting
F. Male clients expect you as a female therapist to be sympathetic.

Male clients expect a male therapist to be sympathetic.

G. Male clients do not expect you as a female therapist to be logical.

Male clients do not expect a male therapist to be logical.

H. Male clients expect you as a female therapist to understand their emotions.

Male clients expect a male therapist to understand their emotions.

I. Male clients do not expect you as a female therapist to understand their life experiences.

Male clients do not expect a male therapist to understand their life experiences.

J. Male clients expect you as a female therapist to be non-judgmental.

Male clients expect a male therapist to be non-judgmental.

K. Male clients expect you as a female therapist to meet needs rather than promote growth.

Last question: Have you had the experience of working with a male co-therapist? If you have, initially were there different expectations of you as compared to your co-therapist? 
RATING SCALE FOR EXPECTATIONS

1. Manipulated

2. Competent

3. Non-Assertive

4. Nurturing

5. Non-Confrontive

6. Sympathetic

7. Logical

8. Understand Emotions

9. Understand Life Experiences

10. Non-Judgmental

11. Response to Needs/ Growth
SA A NO $D \quad$ SD

\begin{tabular}{lllll}
\hline$A$ & $A$ & NO & $D$ & SD
\end{tabular}

SA A NO D SD

SA A NO D SD

SA A NO D SD

$\overline{S A} \quad A \quad N O \quad D \quad S D$

SA A NO D SD

\begin{tabular}{lllll}
\hline$A$ & $A$ & NO & $D$ & $S D$
\end{tabular}

\begin{tabular}{lllll}
\hline$S A$ & $A$ & $N O$ & $D$ & $S D$
\end{tabular}

SA $A$ NO $\quad D \quad$ SD

SA A NO $D$ SD
SA A NO D SD

$\overline{S A}$ A NO D SD

SA A NO $D$ SD

\begin{tabular}{lllll}
\hline$A$ & $A$ & $N O$ & $D$ & $S D$
\end{tabular}

SA A NO D SD

SA A NO D SD

SA A NO D SD

SA A NO D SD

SA A NO D SD

SA A NO D SD

$S A$ A NO DOSD.

SA A NO D SD 
NAME:

\section{DEMOGRAPHIC INFORMATION}

Purpose: to help us define "therapist"

to better understand your frame of reference

I. EDUCATIONAL BACKGROUND

A. Undergraduate

1. What school?

2. Year of graduation?

3. Major emphasis.

B. Graduate

1. What school?

2. Year of graduation?

3. Major emphasis.

C. Other

II. Age

III. WORK EXPERIENCE

A. How long have you had your present job?

B. List previous work experiences (briefly describe your job/ agency):

1.

2.

3.

C. Present job -- (of at least 2 years).

1. Type of agency.

2. Clientele: urban/rural voluntary/non-voluntary educational level socio-economic level race 
3. Your caseload: age: range majority sex: male female

4. Breakdown of time:

$\%$ of your time in therapy (as opposed to consult., admin., corm. org.

\% of your time in 1:1, marital or family

$\%$ of your time in group therapy 


\section{KEY TO EXPECTATION CATEGORIES ON QUESTIONNAIRE}

Statements falling into the Nurturing Category included:

$$
\# 1,7,14,17,18
$$

Statements falling into the Manipulation Category included:

$$
\# 2,4,9,22,31
$$

Statements falling into the Non-Judgmental Category included:

$\# 3,12,13,26$

Statements falling into the Understanding Emotions Category included:

$$
\# 10,11,15,19
$$

Statements falling into the Competence Category included:

$\# 16,20,21,28,29$

Statements falling into the Assertive Category included:

$\# 24,25,27,33,34$

Statements falling into the Life Experience Category included:

$\# 6,8,23,30,32$ 
Uenr Studant.

Th1s questionnalre is part of a research project we are conducting to complote our thesis requirewent at the school of Social work here at

PSU. It is not part of the counsolinp, contor and your partiolpation in p1lling sut this questionnelre is complotely voluntary. The information gather from it 18 confidentiel so please do not put your nave on $1 t$. n's would eppreciete your cooparation in oompleting the questionnalre, placing it in the envelope, and returning it to the box in the counseling centar office. If you have any questions regarding the study, plesese ropl free to cell us at $235-9763$ or $225-0110$. Thanks agein for halpting 15.

Sincerely,

Thyll1s Holns Sucan Orated 


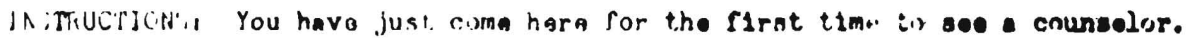
in would lika t.o know more shout what you expect of hill as you onticlpeta your lirst contect with him. Please reapond to each of the followine statomonts by circling, the muber that nost closely exraes with your expectation.

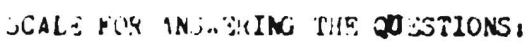

\begin{tabular}{|c|c|c|c|c|}
\hline $\begin{array}{l}\text { jtrontv igrees } \\
\text { wstr ry } \\
\text { sxpectation }\end{array}$ & $\begin{array}{c}\text { Arroes } \\
\text { w1th my } \\
\text { Sxpectation } \\
?\end{array}$ & $\begin{array}{l}\text { Nalther Agroes } \\
\text { Nor Uisegrees } \\
\text { with my } \\
\text { Expectation } \\
3\end{array}$ & $\begin{array}{c}\text { Disagreos } \\
\text { with my } \\
\text { Expeotetion } \\
4\end{array}$ & $\begin{array}{c}\text { StronglJ W1 sagreos } \\
\text { with wy } \\
\text { Expectation } \\
5\end{array}$ \\
\hline
\end{tabular}

1. Ha wlll talk to ne as if I am a child.

\begin{tabular}{|c|c|c|c|}
\hline 1 & 2 & 3 & 4 \\
\hline 1 & 2 & 3 & 4 \\
\hline 1 & 2 & 3 & 4 \\
\hline 1 & 2 & 3 & 4 \\
\hline 1 & 2 & 3 & 4 \\
\hline 1 & 2 & 3 & 4 \\
\hline 1 & 2 & 3 & 4 \\
\hline 1 & 2 & 3 & 4 \\
\hline 1 & 2 & 3 & 4 \\
\hline 1 & 2 & 3 & 4 \\
\hline 1 & 2 & 3 & 4 \\
\hline 1 & 2 & 3 & 4 \\
\hline 1 & 2 & 3 & 4 \\
\hline 1 & 2 & 3 & 4 \\
\hline
\end{tabular}

?. IA 'an racolnien if I am not being totisle honaat.

3. If I laka mistakas, he wlll disapprove of ins.

14. If I choosa to conceal things from him, he wll not eatch on.

'i. in w1ll he Insensitive to the problams that sre most important to mo.

f. Iin cannot umiorstand what military exparlances ora l1ke.

7. Ha will allow me to think for myself.

f. i! can undarstand problems that involve ralationships with tho opposite sex.

y. He cen be decolved by what I sey.

10. If I hlow my top durins; coinselins session, he wlll be sensitive to how I am ragline.

11. If i foul lepressed, ha wlll be impatiant with my foolings.

1?. If I shara negative thoughts, he will disapprove of ma.

13. If our vajuns diffor, ne wlll try to influence ma to accopt his.

1h. in wlll b. pverly concerned about my pronlams.

5

s

;

5

5

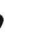

5




\begin{tabular}{|c|c|c|c|c|}
\hline 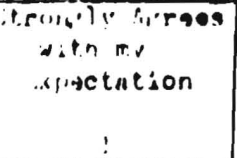 & $\begin{array}{l}\text { huroes } \\
\text { with my } \\
\text { pxpectation }\end{array}$ & 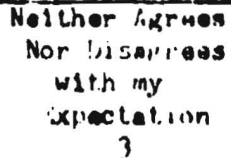 & $\begin{array}{c}\text { Orsarroes } \\
\text { with my } \\
\text { axpectation } \\
4\end{array}$ & $\begin{array}{c}\text { Strongly disagreos } \\
\text { mith ay } \\
\text { axpectation }\end{array}$ \\
\hline
\end{tabular}

15. Ka will undarst.and if I hasitete to in cumplatily open with ay foollnas.

\begin{tabular}{|c|c|c|c|}
\hline 1 & 2 & 3 & 4 \\
\hline 1 & 2 & 3 & 4 \\
\hline 1 & 2 & 3 & 4 \\
\hline 1 & 2 & 3 & 4 \\
\hline 1 & 2 & 3 & 4 \\
\hline 1 & 2 & 3 & 4 \\
\hline 1 & 2 & 3 & 4 \\
\hline 1 & 2 & 3 & 4 \\
\hline 1 & 2 & 3 & 4 \\
\hline 1 & 2 & 3 & 4 \\
\hline 1 & 2 & 3 & 4 \\
\hline 1 & 2 & 3 & 4 \\
\hline 1 & 2 & 3 & 4 \\
\hline 1 & 2 & 3 & 4 \\
\hline 1 & 2 & 3 & 4 \\
\hline 1 & 2 & 3 & 4 \\
\hline
\end{tabular}

16. If my problees sana ovoruhelming, ho w1ll be strone enouph to help with thas. 140245

17. If I raal dlsocuraged, he wlll be ronssurinu.

(1)

12. lia will oncouraga ma to grow as an edult.

19. He wlll bo unconfortable If I feel like crylnp.

20. 40 w1ll Rive edvice whon 14 1s nsproprinta.

21. I0 w1ll negleot to help mo clarify w rouls for couneeling.

22. Ho can ba swayed by my beharlor.

23. 40 can understand the responsibilities of holnu. Pather.

24. He wll interrupt we if I ramble on and on.

75. Wven if he has strong feolings about what I am seyplne, he will hesitute to tell me.

it). No mattor what I sey in the counsoling sessions, he wlll still cooupt mo.

27. If I wanter off the top10, he will Just IIstan.

2H. In w11l not. ba confident. at the start of tha counselint session.

2\%. Ha will usually know how to help me.

30. If I hava sexisel concerns, ho wlll not undarstent there. 


\begin{tabular}{|c|c|c|c|c|}
\hline $\begin{array}{c}\text { Jirnnsly Agraes } \\
\text { with my } \\
\text { ixpectation }\end{array}$ & $\begin{array}{c}\text { Arroes } \\
\text { wth wy } \\
\text { sinectetion } \\
2\end{array}$ & $\begin{array}{l}\text { Weithor Arrees } \\
\text { Nor U1 angees } \\
\text { wth wy } \\
\text { bxpectetion } \\
3\end{array}$ & $\begin{array}{c}\text { Disagrees } \\
\text { with wy } \\
\text { axpectation } \\
4\end{array}$ & $\begin{array}{c}\text { Strongly Deagrees } \\
\text { whth wy } \\
\text { appectation }\end{array}$ \\
\hline
\end{tabular}

31. Ir l coma on as charalna, he wlll be influancel by ma.

1

1

2

3

4

5

3. Ho can understand what it is like to sipport ^ ramily.

1

2

3

4

33. If I am Inconsistent, he w1ll point this out to mo.

1

1

$2 \quad 3 \quad 4 \quad 5$

34. If I a not ueling any counseling sessions productively, he will lot wo know this.

$12 \quad 3 \quad 4 \quad 5$

\section{HaAse angwor the followline questionss}

1. Your are $\ldots$.

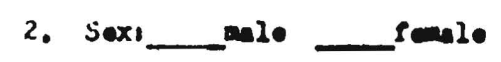

3. Yaar In school, 1234 Grad.

4. Zeason for coming to the counseling centeri (check one or sore) educational vocational porsomel

5. Have you ever sought counseling in the past?

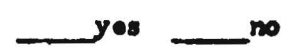

$$
\text { if so, when }
$$

A. at ware tha reasons? (cheok one or wore)

$$
\text { _... educational rocational }
$$

personal

n. ins your counselor/counsnlors ___male or ___enelel (oheck one or wore)

7. What is your preforence for counselor? Male Dena

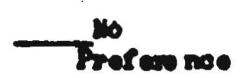


Vear Student,

Th1s questionnalre 1s part of a rescerch project we ere conductins to complete our thesis requircaent at the sohool of Soclel work hore et PSU. It is not part of the counseline, center and your partiolpation in p1link out this queationselre is completely voluntary. The Iriformation gethered from it is confidentiel so please do not put your nano on 1 t. n's would approclete your cooperation in oomploting the questionnire, placing it in the envelope, and returning it to the box in the counseline contar office. If you have any questions regerding the study, please fopl rree to call us at 235-9763 or 225-0110. Thanks eqgeln for helpturg is.

Sincerely.

Phyll1s Helne

sucan Oroted 
INiTrLCILN:j, You have just come here for the flrst tIae to see a counselor. in would likn to know more about what you expect of her as you nnticlpete your flest contact with her. Mlase reopond to each of the followin stat aments by clroling the number that wost closely arrans with your expoctation.

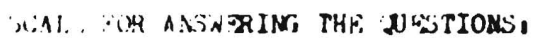

\begin{tabular}{|c|c|c|c|c|}
\hline $\begin{array}{l}\text { Jtronely Aprees } \\
\text { with my } \\
\text { ixpectution }\end{array}$ & $\begin{array}{c}\text { Aprees } \\
\text { with } \\
\text { sxpectation }\end{array}$ & $\begin{array}{l}\text { Nelther Agrees } \\
\text { Vor DI serrees } \\
\text { with my } \\
\text { Pxpectation }\end{array}$ & $\begin{array}{l}\text { Dieagrees } \\
\text { udth wo } \\
\text { expectation }\end{array}$ & $\begin{array}{c}\text { Strongly Wiangreee } \\
\text { with wy } \\
\text { Bxpectation }\end{array}$ \\
\hline 1 & 2 . & & 4 & 5 \\
\hline
\end{tabular}

1. sha will talk to mo as if I am a child.

1

2

3

4

5

$\therefore$ slim can racosiniea $1 f$ I am not beling totally honest.

$\begin{array}{lllll}1 & 2 & 3 & 4 & 5 \\ 1 & 2 & 3 & 4 & 5 \\ 1 & 2 & 3 & 4 & 5 \\ 1 & 2 & 3 & 4 & 5 \\ 1 & 2 & 3 & 4 & 5 \\ 1 & 2 & 3 & 4 & 5 \\ 1 & 2 & 3 & 4 & 5 \\ 1 & 2 & 3 & 4 & 5\end{array}$

$\because$ ihe can !. dacelved by what I say.

11 disepprove

of $\mathrm{me}$.

If I shous to concel thlnes from har, sho will not catch on.

5. ihe w1ll be Insensitive to the probleas thot. ora most important. to ma.

6. She cannot. unfarstant what aslitary axpariances are llka.

7. She wlll nllow me th think for myself.

\&. Sha can uniarstand problans that involve relatilonships wath the opposite sex.

10. If 1 il ow mi top hurine oounseline sasision. sh w1Il be sensitlve to how I AT: Cagling.

\section{1}

11. If I roel tapressad, sha will be Impationt. Wth my Panlinws.

ii. If I Ainra noyatidve thouphts, she wll dl serprova of me.

13. If our valuas diffor, she will try to influancen mo to accopt. hers.

14. ine will the overly concerned about prosiarms.

(a)




\begin{tabular}{|c|c|c|c|c|}
\hline $\begin{array}{c}\text { jtronely taraes } \\
\text { with ay } \\
\text { ixpactation }\end{array}$ & $\begin{array}{c}\text { Agrees } \\
\text { with my } \\
\text { sxpectiotion } \\
2\end{array}$ & $\begin{array}{l}\text { Nelthar Agrees } \\
\text { Nor Disagrees } \\
\text { with my } \\
\text { 3xpectation } \\
3\end{array}$ & $\begin{array}{c}\text { Disagrees } \\
\text { with ay } \\
\text { 5xpectation } \\
4\end{array}$ & 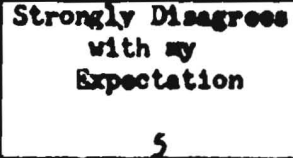 \\
\hline
\end{tabular}

15. Sha wlll undarstand if I hesitate to ta completely open with my foulings.

$\begin{array}{lllll}1 & 2 & 3 & 4 & 5 \\ 1 & 2 & 3 & 4 & 5 \\ 1 & 2 & 3 & 4 & 5 \\ 1 & 2 & 3 & 4 & 5 \\ 1 & 2 & 3 & 4 & 5 \\ 1 & 2 & 3 & 4 & 5\end{array}$
appropriater

21. iho will neal Inct to help me olerify ay goels for counseling.

22. Sha can ba swayad by my behavior.

$\begin{array}{lllll}2 & 3 & 4 & 5\end{array}$

27. Sha can understend the responsibilities of balng. a fathar.

$\begin{array}{lllll}1 & 2 & 3 & 4 & 5 \\ 1 & 2 & 3 & 4 & 5 \\ 1 & 2 & 3 & 4 & 5 \\ 1 & 2 & 3 & 4 & 5 \\ 1 & 2 & 3 & 4 & 5 \\ 1 & 2 & 3 & 4 & 5 \\ 1 & 2 & 3 & 4 & 5\end{array}$

21. ihn will interrupt mo if I ramble on and on.

1

25. Ivan if sho has strone foollngs about what I nm saylno, she w1ll hesitete to inll mo.

26. No mattior what 1 say in the ocunseling sessions, she will still eocopt ao.

$\begin{array}{lllll}1 & 2 & 3 & 4 & 5 \\ 1 & 2 & 3 & 4 & 5 \\ 1 & 2 & 3 & 4 & 5 \\ 1 & 2 & 3 & 4 & 5 \\ 1 & 2 & 3 & 4 & 5 \\ 1 & 2 & 3 & 4 & 5 \\ 1 & 2 & 3 & 4 & 5 \\ 1 & 2 & 3 & 4 & 5\end{array}$

27. If d wantar off tha toplc, she wlll fust isten.

28. The wll not he confident at the start of the counsellno session.

27. The will u:suelty know how to help mo.

30. If I have saxual concerns, she wlll not understand tham. 


\begin{tabular}{|c|c|c|c|c|}
\hline $\begin{array}{c}\text { itringlv Aprons } \\
\text { wath my } \\
\text { iypactetion } \\
1\end{array}$ & $\begin{array}{l}\text { Agroos } \\
\text { with my } \\
\text { ixpoctation } \\
?\end{array}$ & $\begin{array}{l}\text { Nolthar Arrees } \\
\text { Mor Ul sapranes } \\
\text { with my } \\
\text { Expectetion } \\
3\end{array}$ & $\begin{array}{c}\text { Diengreos } \\
\text { mith iny } \\
\text { expectetion } \\
4\end{array}$ & $\begin{array}{c}\text { Strongly Dieagrees } \\
\text { with my } \\
\text { repeotetion } \\
5\end{array}$ \\
\hline
\end{tabular}

31. If I cima on es cherming. she will be influanced by mo.

$\begin{array}{lllll}1 & 2 & 3 & 4 & 5 \\ 1 & 2 & 3 & 4 & 5 \\ 1 & 2 & 3 & 4 & 5 \\ 1 & 2 & 3 & 4 & 5\end{array}$

$\bullet \bullet \bullet \bullet \bullet \bullet \bullet \bullet \bullet \bullet \bullet \bullet \bullet \bullet \bullet \bullet \bullet \bullet \bullet \bullet \bullet \bullet \bullet \bullet \bullet \bullet \bullet \bullet \bullet$

Plania answer the following questionss

1. Your ain

2. Sex: -20 remale

i. Yanr in school 1234 Gred.

14. Heason ror comins to the counseling center, (check one or wore)

_orucetional rocational prorsonal

\%. Heve you over sought counseling in the past? _yos no

If so, whon

What were the rasons? (oheok one or wore)

- hins your counselor/counselors male or porsonal

$\because$ What is your praforence for a counselor? reanler (cheok one or more) Malo renle 